Société d'histoire de la révolution de 1848 et des

révolutions du XIXe siècle

$37 \mid 2008$

L'ère victorienne revisitée

\title{
Louis BLANC, Doctrine de l'État. Plus de Girondins. La République une et indivisible
}

Jean-Claude Caron

\section{OpenEdition}

Journals

Édition électronique

URL : http://journals.openedition.org/rh19/3531

DOl : $10.4000 /$ rh 19.3531

ISSN : $1777-5329$

Éditeur

La Société de 1848

Édition imprimée

Date de publication : 15 novembre 2008

Pagination : 185-242

ISSN : 1265-1354

Référence électronique

Jean-Claude Caron " Louis BLANC, Doctrine de l'État. Plus de Girondins. La République une et indivisible », Revue d'histoire du XIXe siècle [En ligne], 37 | 2008, mis en ligne le 01 décembre 2008, consulté le 22 septembre 2020. URL : http://journals.openedition.org/rh19/3531 ; DOI : https://doi.org/10.4000/ rh19.3531

Ce document a été généré automatiquement le 22 septembre 2020

Tous droits réservés 


\title{
Louis BLANC, Doctrine de l'État. Plus de Girondins. La République une et indivisible
}

\author{
Jean-Claude Caron
}

\section{RÉFÉRENCE}

Louis BLANC,Doctrine de l'État. Plus de Girondins. La République une et indivisible, Uzès, Inclinaison, 2008, 188 p. ISBN : 978-2-916942-04-9. 15 euros.

1 L'édition de ces trois textes de Louis Blanc est précédée d'une contribution d'Hélène Desbrousses, «Louis Blanc : un apport théorique et historique controversé », et suivie d'une étude d'Armelle Le Bras-Chopard, «Proudhon, Louis Blanc et Pierre Leroux: polémique sur la question de l'État », déjà publiée en 1993 dans ce qui était alors le bulletin de notre Société, 1848. Révolutions et mutations au XIXe siècle. La fortune politique, historique et éditoriale de Louis Blanc a connu des aléas, que s'est ingénié à comprendre le colloque organisé par Francis Démier à l'université de Paris X-Nanterre, dont les actes ont été édités par Créaphis en 2005 (Louis Blanc, un socialiste en République, un volume qui ne semble pas cité dans l'article introductif). C'est peu dire, comme le révéla ce colloque, que les sentiments et les opinions restent très partagés quant à l'apport théorique et à l'action politique de l'auteur de l'Organisation du travail et de l'inventeur des ateliers sociaux.

2 Rédigés entre 1849 et 1851 , ces textes conçus dans l'exil anglais ne révèlent rien que l'on ne sache déjà de Louis Blanc. Partisan de la centralisation montagnarde, de la République une et indivisible, unitaire sans état d'âme, Louis Blanc ferraille contre le fédéralisme proudhonien et le municipalisme de Ledru-Rollin. Sa Doctrine de l'État fait de ce dernier le bras armé qui doit donner corps à une pleine et entière souveraineté populaire. La dissolution de l'État envisagée par Proudhon ne conduira qu'au chaos, au mieux au renforcement du pouvoir des puissants sur les faibles, comme l'État libéral. La 
forme-État envisagée par Louis Blanc est celle d'un «État serviteur " qu'il oppose à l'« État maître ». Ce texte polémique se révèle également intéressant par sa réflexion sur la notion de souveraineté du Peuple (avec majuscule) et sur le contenu de ce Peuple qui est au cœur de la théorie blanciste. Or, cet « être collectif» ne peut se réaliser que dans l'état, gage de l'autonomie du Peuple, de la liberté et de l'égalité.

Dans le second texte, qui relève du même combat, Louis Blanc entend répondre à des textes de Rittinghausen, Considerant et Ledru-Rollin. Comme son titre l'indique, Plus de Girondins s'inscrit dans une historicité davantage marquée. Louis Blanc s'adosse à la pensée de Montesquieu, de Rousseau (dont un extrait du Contrat social est ainsi analysé : "C'est le socialisme pressenti») et de Robespierre pour défendre l'idée d'un gouvernement centralisé et repousser un système qui ferait des 37000 communes françaises autant de petits gouvernements ou de « petits parlements rivaux »- « 37000 tronçons épars de République ». Le suffrage universel deviendrait alors, dit joliment Louis Blanc, un «babélisme universel ». Admirateur de la Constitution de l'an I, dont il reconnaît toutefois les imperfections, Louis Blanc continue de défendre l'idée de centralisation, appuyée sur une puissante représentation nationale, et se montre très circonspect envers tout ce qui confierait aux communes un pouvoir jugé dangereux dans ses effets au vu de " l'état d'ignorance où sont les campagnes, sous l'empire des préjugés partout répandus ». À l'évidence, le traumatisme engendré par le résultat des élections d'avril 1848 demeure vif. Pour Louis Blanc, qui s'arc-boute sur une formule résumant son socialisme, " de chacun selon ses facultés, à chacun selon ses besoins ", le gouvernement direct de tous par tous impose un aménagement du législatif, avec en particulier des représentants élus, responsables et révocables.

La République une et indivisible enfonce le clou en reprenant le débat avec Ledru-Rollin, ex-collègue de gouvernement de Louis Blanc et compagnon d'exil anglais. Là encore, le propos est fortement historicisé, et ce sont à la fois les Lumières et la Révolution française qui sont sollicitées, Rousseau et Robespierre tout particulièrement. Louis Blanc y précise ce qu'il entend par centralisation: autant la centralisation politique (née avec la Révolution) lui semble nécessaire, autant la centralisation administrative (œuvre de Napoléon Bonaparte) lui semble détestable. Il y détaille ce que lui, " républicain socialiste et révolutionnaire », entend par République une et indivisible. Il reprend aussi, pour en faire une identité proclamée, le qualificatif d'utopiste et dit (modérément) le bien qu'il pense de la pensée de Fourier, Cabet ou Leroux. En définitive, les deux pôles que rejettent avec force Louis Blanc (Ledru-Rollin et Proudhon) le sont pour cause de libéralisme commun, bien que, pour le reste, un fossé sépare la pensée du « démoc-soc » de celle de l'anarchiste. Il faut lire Louis Blanc, non pour réévaluer ou inverser une hiérarchie des talents dans l'histoire de la pensée ou de la théorie politique, mais pour y percevoir une sensibilité très française, héritage revendiqué d'une Révolution montagnarde considérée comme la matrice du socialisme. 